Review Article

\title{
COVID-19: Malaysia's fight against this deadly virus
}

\author{
Article History \\ Received: 19 May 2021; \\ Received in Revised Form: \\ 29 May 2021; \\ Accepted: 31 May 2021; \\ Available Online: 2 June \\ 2021
}

Ke-Yan Loo ${ }^{1}$, Vengadesh Letchumanan ${ }^{1^{*}}$

\author{
${ }^{1}$ Novel Bacteria and Drug Discovery (NBDD) Research Group, Microbiome \\ and Bioresource Research Strength (MBRS), Jeffrey Cheah School of \\ Medicine and Health Sciences, Monash University Malaysia, 47500, Selangor \\ Darul Ehsan, Malaysia; ke.loo@monash.edu (K-YL)
}

*Corresponding author: Vengadesh Letchumanan; vengadesh.letchumanan1@monash.edu (VL)

\begin{abstract}
Malaysians are facing the biggest challenge in 2021 - the rise in COVID-19 cases and its variant of concern (VOC) strains. The scale and impact of this coronavirus disease are unimaginable, scary, and full of sorrows. Many lost their loved ones, relatives, friends, and children are becoming orphaned overnight. Now our only hope is on the available vaccines to control this deadly virus infection. When this Review article was in press, over 170 million confirmed cases with 3.5 million deaths were reported worldwide. Malaysia is dealing with spikes in the number and severity of new cases. A record toll of new cases and fatalities for consecutive weeks has pushed Malaysia's total cases to a soaring 500,000 confirmed cases with 2300 deaths - the third highest in Southeast Asia behind Indonesia and the Philippines. The healthcare system in Malaysia is currently under heavy pressure to control the disease as the number of confirmed cases is rising exponentially. A National COVID-19 Immunization Program was launched in February 2021 in the hope of providing immunity to $80 \%$ of the population in Malaysia and achieve herd immunity. This review discusses the alarming COVID-19 situation in Malaysia, the management strategies, and the vaccinations program.
\end{abstract}

Keywords: COVID-19; novel coronavirus; Malaysia; vaccination; herd immunity

\section{Introduction}

It has been over a year since the World Health Organization (WHO) declared COVID-19 as a global pandemic caused by the novel severe acute respiratory syndrome coronavirus 2 (SARS-CoV-2) ${ }^{[1-5]}$. This virus has vastly spread worldwide, with new variants becoming a source of concern as the variants are associated with higher infectivity linked to high fatality rates ${ }^{[6,7]}$. The total number of confirmed cases has surpassed 170 million, and 3.5 million deaths reported globally ${ }^{[8]}$. In 2020, vaccines were developed pharmaceuticals at warp speed to overcome the burden of COVID-19 ${ }^{[9]}$. In November 2020, Pfizer officially announced that their vaccine has a $95 \%$ efficacy against this virus and subsequently rolled out the vaccine for use in December. Since then, various other vaccines with considerable efficiency against COVID-19 were produced by pharmaceutical companies; for example, Moderna, AstraZeneca, Sinovac, etc. have also been distributed worldwide to fight against 
the pandemic ${ }^{[9,10]}$. Cumulatively, more than 1.4 billion vaccine doses have been administered internationally ${ }^{[8]}$.

Malaysia's fight against COVID-19 started in early 2020. Soon after the COVID-19 outbreak in China, the first cases of COVID-19 were detected in Malaysia on $25^{\text {th }}$ January $2020^{[11]}$. The cases involved three Chinese nationals who were close contacts of an elderly COVID-19 patient receiving treatment in Singapore. The Chinese nationals were part of a group of eight placed under quarantine in Johor Bahru after traveling into Malaysia via Singapore on the $24^{\text {th }}$ of January $2020^{[12]}$. The three Chinese nationals were then moved to the Sungai Buloh Hospital in Selangor for treatment ${ }^{[13]}$. The Ministry of Health Malaysia $(\mathrm{MOH})$ quickly released a statement notifying the public about the confirmed COVID-19 cases. It urged the public to practice good personal hygiene i.e., hand washing, wearing face masks, social distancing, and avoid large social gatherings or crowded areas to prevent the spread of the virus. Individuals who displayed symptoms of difficulty in breathing and fevers should also seek treatment immediately. On the $4^{\text {th }}$ of February 2020, a 41-year-old man became the first Malaysian to be tested positive for the coronavirus. He had just returned to Malaysia from Singapore and had developed symptoms of fever and cough. He was referred to Sungai Buloh Hospital and admitted to an isolation ward ${ }^{[14]}$. Just two days later, his younger sister was tested positive for the virus, and this became the first case of local transmission of the SARS-CoV-2 virus in Malaysia ${ }^{[15]}$.

The Malaysian government took various precaution measures and imposed restrictions throughout the country to control the spread of this virus. Malaysians started to live and adapt to the "New Normal" life, which caused a significant impact on the economic, social, and livelihoods ${ }^{[16]}$. A National COVID-19 Immunization Program was launched in February 2021, in the hope of providing immunity to $80 \%$ of the population in Malaysia and achieve herd immunity. As of 22 May 2021, around 3\% of the nation's population is fully vaccinated. This review aims to provide insights into the alarming COVID-19 situation, management strategies, and vaccination status in Malaysia.

\section{COVID-19 Cases in Malaysia}

Initially, the number of confirmed cases in Malaysia was growing slowly, but in March 2020, there was a sudden exponential increase in the cases. The cases were traced back to a religious event held in Sri Petaling, Kuala Lumpur, which amassed 16,000 local participants and 1,500 foreign participants ${ }^{[17]}$. The abrupt spike in cases pushed the government to close its borders to the world as a preventative measure. Prompted by the rapidly increasing number of cases in Malaysia, the Prime Minister of Malaysia also announced the first Movement Control Order (MCO) on $16^{\text {th }}$ March $2020^{[18]}$. During this period, all mass movements and gatherings were prohibited, and only essential services could operate across the country. The government completely prohibited all interstate, inter-district, or international traveling during this time. The MCO, which was scheduled to end on the $31^{\text {st }}$ of March, got extended until $4^{\text {th }}$ May 2020 to further prevent the spread of the virus. A Conditional Movement Control Order (CMCO) was then implemented from $4^{\text {th }}$ May to $9^{\text {th }}$ 
June 2020, whereby the lockdown restrictions were slightly loosened, and certain business sectors were allowed to resume operations ${ }^{[19]}$. The Prime Minister of Malaysia then announced that the CMCO would end and be replaced by the Recovery Movement Control Order (RMCO) on $9^{\text {th }}$ June as the COVID-19 cases were well under control. Interstate travel was now allowed, and almost all businesses, educational, religious, and social activities could resume under strict standard of procedures during the RMCO. Malaysians were still reminded to wear face masks when in public areas, practice social distancing, avoid crowded areas, and practice good hygiene to prevent a new wave of virus spread. However, amidst the RMCO, positive cases hit an all-time high in October, reaching over 800 cases due to many individuals traveling interstate in September to vote in the state election in Sabah ${ }^{[20]}$. This contributed to the third wave of infections in Malaysia as the number of confirmed positive cases in Malaysia continued to soar, hitting record high numbers and grew in an upwards trend up until $29^{\text {th }}$ January 2021 where cases peaked at 5,725 cases $^{[21]}$. There was a steady decrease in the daily cases until early April 2021; then, cases began to increase rapidly once more going into May 2021. The cases were increasing at an alarming rate in less than two months, and 9,020 cases were reported on $29^{\text {th }}$ May 2021, surpassing the previous record (Figure 1). The daily number of deaths due to COVID-19 has also been rising, reaching 98 deaths a day on $29^{\text {th }}$ May 2021. The spike in cases further overwhelmed the public healthcare system in Malaysia, which was already under heavy pressure from handling COVID-19 cases since 2020.

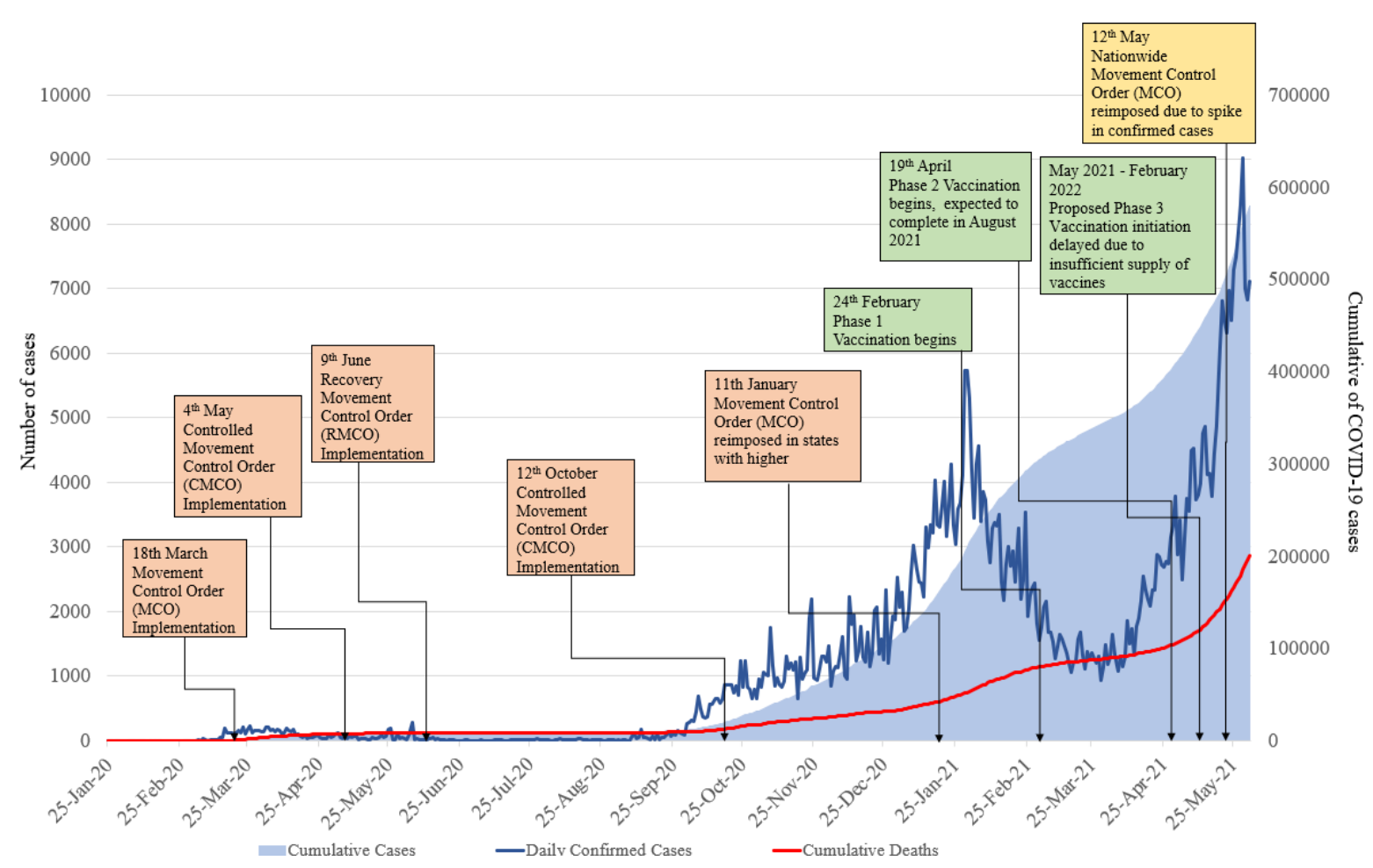

Figure 1. Illustration of daily confirmed COVID-19 cases, cumulative COVID-19 cases, cumulative deaths due to COVID19, and a brief timeline of the events in Malaysia since the beginning of the COVID-19 pandemic in 2020. 


\section{Vaccination in Malaysia}

Despite the rising number of cases, the government has drawn up various strategies and continues to control coronavirus spread in Malaysia. The earliest efforts were to enforce health screenings at all points of entry to detect fever among individuals. The number of hospitals that could treat COVID-19 was also increased to accommodate the rising numbers of confirmed cases of infection. Strict rules and regulations devised during the MCOs aimed to prevent the further spread of the virus into local communities ${ }^{[22]}$. Standard operating procedures (SOP) were implemented in workplaces to reduce staff capacity, social distancing, prohibition of mass gatherings, face mask-wearing, etc., to prevent disseminating the virus into local communities ${ }^{[23]}$.

Furthermore, at-risk individuals within identified clusters were tracked down via contact tracing to undergo COVID-19 screening and would serve as a mandatory home surveillance order ${ }^{[24]}$. The Ministry of Health $(\mathrm{MOH})$ also raised awareness for COVID-19 via mass media infographics to continuously remind the public of the preventative measures that can be taken to prevent COVID-19 infections. In addition, the MOH would update the people on the number of confirmed cases, total deaths, and total recoveries daily on their website $^{[25]}$. The press briefings, conference recordings, and relevant news on COVID-19 are also frequently updated by the Malaysian government and the $\mathrm{MOH}$.

As the roll-out of vaccines developed by Pfizer, AstraZeneca, and Sinovac began worldwide, the Malaysian government has been placing orders for these vaccines since November $2020^{[26-28]}$. Additional orders for the vaccines were placed in 2021 to speed up the vaccination process in Malaysia to achieve the target of providing immunity to $80 \%$ of its 32 million population by February 2022. The first batch of 312,390 doses of the Pfizer vaccine arrived on the $21^{\text {st }}$ February 2021, while 268,000 doses of the AstraZeneca vaccine were received on $23^{\text {rd }}$ April 2021 $1^{[29-31]}$. As for the vaccine doses from Sinovac, 200 litres of bulk vaccine arrived from China on $27^{\text {th }}$ February and were filled and finished at the Pharmaniaga LifeScience Sdn Bhd (PLS) plant. As of $10^{\text {th }}$ May, PLS has prepared 1.2 million doses of Sinovac vaccines, and 290,480 doses have been approved by the National Pharmaceutical Regulatory Agency (NPRA) for distribution ${ }^{[31]}$. More vaccine shipments have since arrived in Malaysia in the months following the first batches. These vaccines would be distributed freely upon registration to Malaysians and foreigners residing in Malaysia, with Malaysians receiving priority. The vaccines would also be distributed through the COVID-19 Immunization Programme in three phases, with the first phase completed in April 2021. While the target for Phase 1 was to administer 500,000 doses of vaccines, 552,682 doses were distributed with an average of 23,410 daily doses. The first phase prioritized front liners, whereas phase two prioritizes individuals in high-risk groups such as senior citizens and those with chronic disease. Phase two is scheduled to complete in August 2021, while phase three would prioritize the adult population over 18 years old $\mathrm{d}^{[32]}$. 
The COVID-19 Vaccination Programme in Malaysia has been distributing vaccines from Pfizer (Comirnaty), AstraZeneca (Vaxzevria), and Sinovac (CoronaVac) to the public since February 2021 ${ }^{[33]}$. A study was done in 2020 that studied the intent of Malaysian nationals to receive the COVID-19 vaccine revealed a high overall acceptance of a vaccine, with almost half of the participants expressing a definite intention to take the vaccine and $45 \%$ of participants expressing a possible and probable intention. The study also showed that participants were more likely to have a definite intention of receiving the vaccine if they had a high perception of benefits and low perception barriers in receiving the vaccine, along with high perceived susceptibility of getting a COVID-19 infection ${ }^{[34]}$. Thus, the government and $\mathrm{MOH}$ have been continuously promoting the benefits of receiving the vaccination while reducing the barriers of receiving the vaccines, such as distributing the vaccines free of charge and setting up many vaccination centers countrywide to expand the outreach of the vaccines.

Since the global distribution of the COVID-19 vaccines, many have been concerned about the adverse events that may occur upon receiving vaccines of specific brands. The vaccines used in Malaysia have shown little to no side effects detrimental to the individual's health. The most common side effects are local pain at the injection site, sore muscles, fever, and fatigue post-vaccination. These side effects are generally well tolerated and subside in 12 days $^{[35-37]}$. To note, only Pfizer vaccine is recommended for pregnant or breastfeeding mothers as there is insufficient data to show the safety of the AstraZeneca and Sinovac vaccines in these demographics. Although severe adverse events may occur, these instances are extremely rare. The $\mathrm{MOH}$ has set up the vaccination system so that upon receiving the vaccine, recipients are to be observed for a period to enable swift detection of serious adverse events on the off chance that they occur. These measures ensure that the adverse events following immunization can be treated and monitored at an earlier stage ${ }^{[33]}$. However, the AstraZeneca vaccines raised concerns from the public in Malaysia. This was due to incidents that occurred abroad whereby individuals developed thrombosis with thrombocytopenia syndrome (TTS) post vaccination with the AstraZeneca vaccine ${ }^{[38,39]}$.

Further analyses done by researchers have shown that the occurrence of blood clotting combined with low platelet counts caused by the vaccine is relatively low. The risks of TTS have been shown to occur approximately 4 cases per 1 million, further indicating that the benefits of taking the vaccine greatly outweigh the risks ${ }^{[40]}$. Considering the public's concerns, the Malaysian government opened bookings to the public for the AstraZeneca COVID-19 vaccines in May voluntarily. In addition, the vaccine would not be included in the mainstream national vaccination program and will be distributed only to those who want $\mathrm{it}^{[41]}$. The first round of registration for voluntary vaccination with the United Kingdom developed vaccine opened on $2^{\text {nd }}$ May and are to be distributed within Klang Valley. All 268,000 doses were booked within the first three hours, and the doses were administered in May. To date, no severe side effects from the AstraZeneca vaccine have been reported in Malaysia ${ }^{[42]}$. The second round of registration for 1.1 million doses of the vaccine opened from $23^{\text {rd }}$ May to $26^{\text {th }}$ May. High-risk groups and individuals over 60 years of age were prioritized during this 
round of voluntary opt-ins. The supply of vaccines will be extended to Penang, Sarawak, and Johor, currently in the COVID-19 red zones ${ }^{[43]}$. According to data released by The Special Committee On COVID-19 Vaccine Supply (JKJAV), now, over 2 million individuals have received the COVID-19 vaccine, and over 12.2 million have registered to receive the vaccine. To date, approximately $6.2 \%$ of the population has received at least one dose of the vaccine (Figure 2) ${ }^{[44,45]}$.

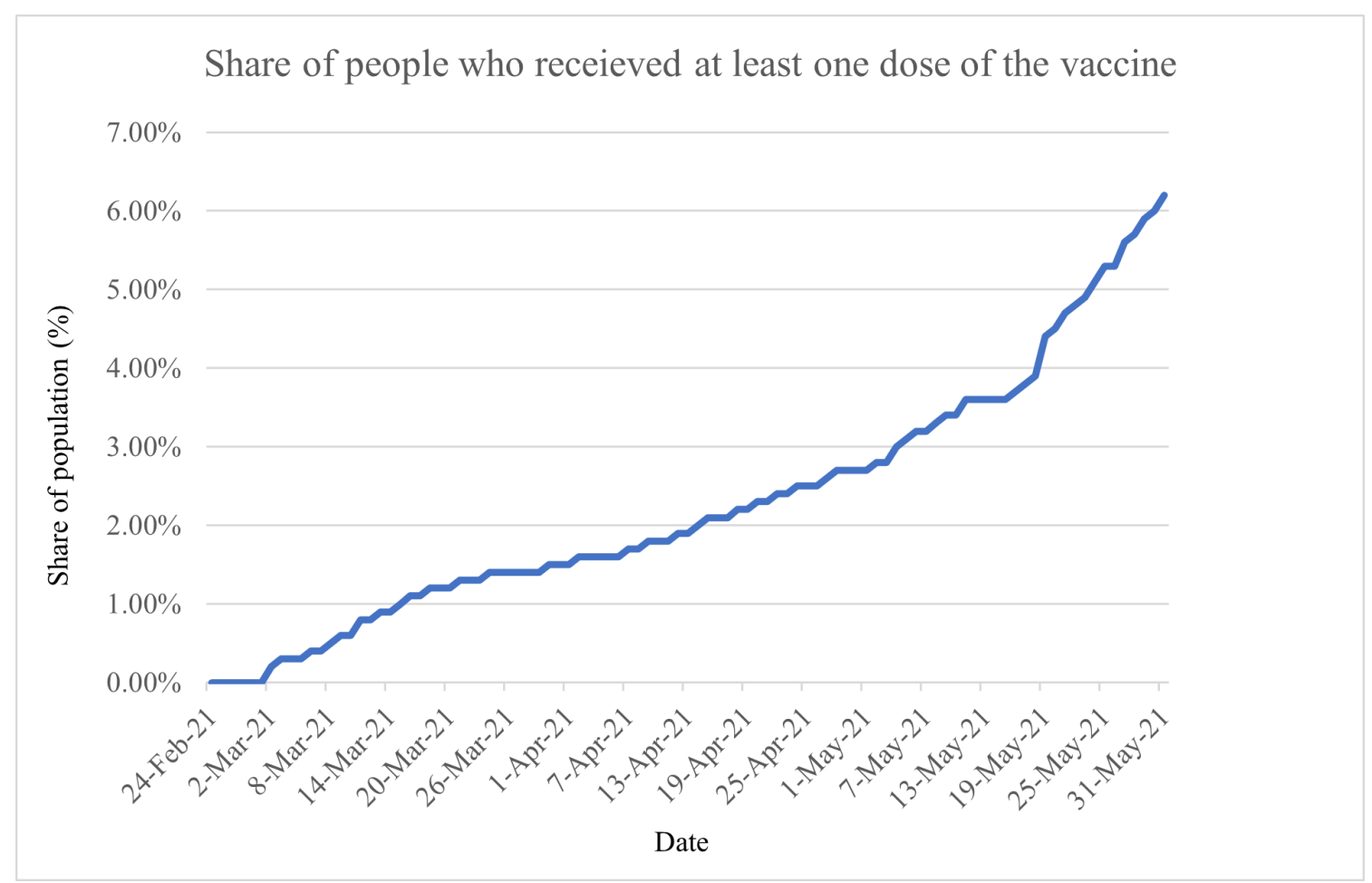

Figure 2. An illustration of Malaysian who shared their experience receiving at least one dose of COVID- 19 vaccine on social media.

\section{The Emergence of VOC Strains}

When this review writing went into press, the number of COVID-19 positive cases and deaths in Malaysia rose to historic heights. Both the public and private healthcare sectors are greatly overwhelmed by the number of confirmed cases. Intensive care units in many hospitals are fully occupied with COVID-19 patients in severe conditions, and quarantine centers are filled with COVID-19 patients. At the beginning of the outbreak of COVID-19 in Malaysia, researchers analyzed 58 SARS-CoV-2 genome sequences from COVID-19 patients in Malaysia. They determined that the major contributor of the disease transmission in Malaysia was the SARS-CoV-2 lineage B.6 ${ }^{[46]}$. As the outbreak progressed and more confirmed cases were reported, different variants of the coronavirus were isolated in Malaysia. For instance, in Pahang, SARS-CoV-2 with D614G mutation was found in an asymptomatic patient and this mutation resulted in higher infectivity of the coronavirus ${ }^{[47]}$. Other variants of concern (VOC ) strains include the SARS-CoV-2 lineage B.1.351 (South African), B.117 (United Kingdom), and B.1.617.1 (Indian). To note, these three variants have raised the concern of the $\mathrm{MOH}$ as individuals infected with this variant typically appear 
asymptomatic and would present negative test results during COVID-19 screenings. Those infected would not experience any typical COVID-19 symptoms such as fevers or loss of smell or taste, but signs of pneumonia would be shown through X-ray scans ${ }^{[6,48]}$. These variants were also linked to high fatality rates. The emergence of these variants raises concerns of many regarding the efficacy of the vaccines currently available to the public. Data from Qatar suggested that the Pfizer vaccine was effective against infection and disease within Qatar's population, where the B.1.1.7 and B.1.351 variants were the major causes of infection in the country ${ }^{[49]}$. Meanwhile, in a study conducted in South Africa, it was found that the AstraZeneca vaccine was not effective in protecting against the South African variant ${ }^{[50]}$. A study by Public Health England produced data revealing two doses of the Pfizer vaccine was $88 \%$ while two doses of the AstraZeneca vaccine were $60 \%$ effective against symptomatic diseases from the Indian variant of the coronavirus ${ }^{[51]}$. As for the vaccine from Sinovac, there is insufficient data to confirm whether the vaccine is effective against the variants.

As the situation in Malaysia progresses with the rise of more COVID-19 variants, there is a dire need for a rapid vaccine rollout in Malaysia to protect the population's health. The rate of vaccine distribution is influenced by the supply of vaccines from the manufacturers. As aforementioned, Malaysia will be receiving more shipments of vaccines in the coming months. Henceforth, individuals are highly encouraged to register for the vaccine to achieve immunity against COVID-19 within the nation as soon as possible. While waiting for more vaccines to arrive, the public should play their responsibility in flattening the curve by practicing good hygiene, wearing face masks in public areas, avoiding social gatherings, and obeying all the SOP implemented by the government. Recently, the Health Director General (MOH) shared effective ways of double masking; by using a surgical mask on the inside and a cloth mask on the outside. According to America's Center for Disease Control (CDC), this method provides up to $85.4 \%$ protection compared to $56.1 \%$ when wearing a single 3-ply surgical mask. If the cases continue to rise, the Malaysian healthcare system may collapse, and the disease's burden can no longer be controlled, ultimately crippling the lives of millions in the physical, mental, and economic aspects. It is crucial to note that the betterment of the COVID-19 situation in Malaysia ultimately depends on the combined efforts of the Malaysian government, the Malaysian healthcare system, and the nation.

Author Contributions: K-Y.L performed the literature search, critical data analysis as well as manuscript writing. VL proofread the review writing and conceptualize this review writing project.

Funding: The SEED Funding funded this work from Microbiome and Bioresource Research Strength (MBRS), Jeffrey Cheah School of Medicine and Health Sciences, (Vote Number: MBRS/JCSMHS/02/2020) and Jeffrey Cheah School of Medicine and Health Sciences (JCSMHS) Strategic Grant 2021 (Grant Code: STG-000051).

Conflicts of Interest: The authors declare no conflict of interest.

Acknowledgments: The authors would like to acknowledge Professor Shajahan Yasin, Head of School, Jeffrey Cheah School of Medicine and Health Sciences, Monash University Malaysia. 


\section{References}

1. World Health Organization (WHO). Timeline: WHO's COVID-19 response 2021 [Accessed 2021 May 20]; Available from: https://www.who.int/emergencies/diseases/novel-coronavirus2019/interactive-timeline\#event-7.

2. Goh HP, Mahari WI, Ahad NI, et al., Risk factors affecting COVID-19 case fatality rate: A quantitative analysis of top 50 affected countries. Prog Microbes Mol Biol 2020; 3: 1-7.

3. Tan LT-H, Letchumanan V, Ser H-L, et al., PMMB COVID-19 Bulletin: United Kingdom (22nd April 2020). Prog Microbes Mol Biol 2020; 3(1).

4. Ser H-L, Letchumanan V, Law JW-F, et al., PMMB COVID-19 Bulletin: Spain (18th April 2020). Prog Microbes Mol Biol 2020; 3(1).

5. Lee VS, Chong WL, Sukumaran SD, et al., Computational screening and identifying binding interaction of anti-viral and anti-malarial drugs: Toward the potential cure for SARS-CoV-2. Prog Drug Discov Biomed Sci 2020; 3(1).

6. Centers for Disease Control and Prevention (CDC). Science Brief: Emerging SARS-CoV-2 Variants. 2021 [Accessed 2021 May 21]; Available from: https://www.cdc.gov/coronavirus/2019ncov/science/science-briefs/scientific-brief-emerging-variants.html.

7. Loh HC, Seah YK, and Looi I, The COVID-19 pandemic and diet change. Prog. Microbes Mol. Biol. 2021; 4(1), a0000203.

8. World Health Organization (WHO). WHO Coronavirus (COVID-19) Dashboard. 2021; Available from: https://covid19.who.int/.

9. Loo K-Y, Letchumanan V, Ser H-L, et al., COVID-19: Insights into potential vaccines. Microorganisms 2021; 9(3): 605.

10. Baraniuk C, Covid-19: What do we know about Sputnik V and other Russian vaccines? BMJ 2021; 372: n743.

11. Shah AUM, Safri SNA, Thevadas R, et al., COVID-19 outbreak in Malaysia: Actions taken by the Malaysian government. Int J Infect Dis 2020; 97: 108-116.

12. Ser H-L, Tan LT-H, Law JW-F, et al., Genomic analysis of severe acute respiratory syndrome coronavirus 2 (SARS-CoV-2) strains isolated in Malaysia. Prog. Microbes Mol. Biol. 2020; 3(1).

13. 3 coronavirus cases confirmed in Johor Baru. New Straits Times 2020; Available from: https://www.nst.com.my/news/nation/2020/01/559563/breaking-3-coronavirus-cases-confirmedjohor-baru.

14. First case of Malaysian positive for coronavirus. 2020 [Accessed 2021 May 21]; Available from: https://www.bernama.com/en/general/news_covid-19.php?id=1811373.

15. Coronavirus: Malaysia records first local transmission. 2020 [Accessed 2021 May 21]; Available from: https://www.bernama.com/en/general/news.php?id=1811990.

16. Johnson D, Ren SEC, Johnson HD, et al., COVID-19: Are Malaysians embracing or suffering the new normality? Prog Microbes Mol Biol 2020; 3(1).

17. Barker A. Coronavirus COVID-19 cases spiked across Asia after a mass gathering in Malaysia. This is how it caught the countries by surprise. 2020 [Accessed 2021 May 21]; Available from: https://www.abc.net.au/news/2020-03-19/coronavirus-spread-from-malaysian-event-to-multiplecountries/12066092. 
18. Tang KHD, Movement control as an effective measure against Covid-19 spread in Malaysia: an overview. J Public Health 2020: 1-4.

19. Tho X-Y. Malaysia's movement control order to go into 'recovery phase' until Aug 31: PM Muhyiddin. 2020 [Accessed 2021 May 21]; Available from: https://www.channelnewsasia.com/news/asia/malaysia-s-movement-control-order-to-go-intorecovery-phase-12813004.

20. Sukumaran T. Coronavirus Malaysia: PM blames Sabah election as among causes of huge infection surge. 2020 [Accessed 2021 May 21]; Available from: https://www.scmp.com/week-asia/healthenvironment/article/3104421/coronavirus-malaysia-pm-blames-sabah-election-among.

21. Ministry of Health Malaysia (MoH). COVID-19 Situation in Malaysia - 25 January 2021. 2021 [Accessed 2021 May 21]; Available from: http://covid-19.moh.gov.my/terkini/2021/01/situasi-terkinicovid-19-di-malaysia-25012021.

22. Shah AUM, Safri SNA, Thevadas R, et al., COVID-19 outbreak in Malaysia: Actions taken by the Malaysian government. Int J Infect Dis 2020; 97: 108-116.

23. Letchumanan V, Ab Mutalib N-S, Goh B-H, et al., Novel coronavirus 2019-nCoV: Could this virus become a possible global pandemic. Prog Microbes Mol Biol 2020; 3(1).

24. Aziz NA, Othman J, Lugova H, et al., Malaysia's approach in handling COVID-19 onslaught: Report on the Movement Control Order (MCO) and targeted screening to reduce community infection rate and impact on public health and economy. J Infect Public Health 2020; 13(12): 1823-1829.

25. Ministry of Health Malaysia (MoH). Latest COVID-19 Situation in Malaysia. 2021; Available from: http://covid-19.moh.gov.my/terkini.

26. Malaysia agrees to buy 12.8 million doses of Pfizer's COVID-19 vaccine. 2020 [Accessed 2021 May 21]; Available from: https://www.channelnewsasia.com/news/asia/malaysia-covid-19-pfizer-vaccinecoronavirus-13651672.

27. Dr Adham: Govt to seal vaccine purchase with AstraZeneca on Monday. 2020 [Accessed 2021 May 21]; Available from: https://www.malaymail.com/news/malaysia/2020/12/19/dr-adham-govt-to-sealvaccine-purchase-with-astrazeneca-on-monday/1933446.

28. Malaysia, China ink agreement for vaccine access. 2020 [Accessed 2021 May 21]; Available from: https://www.nst.com.my/news/nation/2020/11/642286/malaysia-china-ink-agreement-vaccineaccess.

29. Tee K. First shipment of Pfizer-BioNTech Covid-19 vaccine arrives in Malaysia. 2021 [Accessed 2021 May 21]; Available from: https://www.malaymail.com/news/malaysia/2021/02/21/firstshipment-of-pfizer-biontech-covid-19-vaccine-arrives-in-malaysia/1951544.

30. Malaysia receives first batch of AstraZeneca COVID-19 vaccines. 2021 [Accessed 2021 May 21]; Available from: https://www.channelnewsasia.com/news/asia/malaysia-receives-first-batch-ofastrazeneca-covid-19-vaccines-14686352.

31. Kaos Jr. J. First batch of Sinovac vaccines prepared in Malaysia ready to roll out. 2021 [Accessed 2021 May 21]; Available from: https://www.thestar.com.my/news/nation/2021/05/11/first-batch-ofsinovac-vaccines-prepared-in-malaysia-ready-to-roll-out.

32. The Special Committee for Ensuring Acess to COVID-10 Vaccine Supply (JKJAV) 2021, National COVID-19 Immunisation Programme. 2021, The Secretariat of the Special Committee for Ensuring Access to COVID-19 Vaccine Supply (JKJAV). 
33. World Health Organization (WHO). Statement on the benefits of vaccines against COVID-19. 2021 [Accessed 2021 May 21]; Available from: https://www.who.int/malaysia/news/detail/30-04-2021statement-on-the-benefits-of-vaccines-against-covid-19.

34. Wong LP, Alias H, Wong P-F, et al., The use of the health belief model to assess predictors of intent to receive the COVID-19 vaccine and willingness to pay. Hum Vaccin Immunother 2020; 16(9): 22042214.

35. Zhang Y, Zeng G, Pan H, et al., Safety, tolerability, and immunogenicity of an inactivated SARSCoV-2 vaccine in healthy adults aged $18-59$ years: A randomised, double-blind, placebo-controlled, phase 1/2 clinical trial. Lancet Infect Dis 2021; 21(2): 181-192.

36. Polack FP, Thomas SJ, Kitchin N, et al., Safety and efficacy of the BNT162b2 mRNA Covid-19 vaccine. N Engl J Med 2020; 383(27): 2603-2615.

37. Knoll MD and Wonodi C, Oxford-AstraZeneca COVID-19 vaccine efficacy. Lancet 2021; 397(10269): 72-74.

38. Wise J, Covid-19: European countries suspend use of Oxford-AstraZeneca vaccine after reports of blood clots. 2021, British Medical Journal Publishing Group.

39. Pottegård A, Lund LC, Karlstad Ø, et al., Arterial events, venous thromboembolism, thrombocytopenia, and bleeding after vaccination with Oxford-AstraZeneca ChAdOx1-S in Denmark and Norway: population based cohort study. BMJ 2021; 373.

40. World Health Organization (WHO). Interim recommendations for use of the ChAdOx1-S [recombinant] vaccine against COVID-19 (AstraZeneca COVID-19 vaccine AZD1222, SII Covishield, SK Bioscience). 2021 [Accessed 2021 May 21]; Available from: https://www.who.int/publications/i/item/WHO-2019-nCoV-vaccines-SAGE_recommendationAZD1222-2021.1.

41. Yusof T-A. Bookings for AstraZeneca vaccine start tomorrow. 2021 [Accessed 2021 May 21]; Available from: https://www.nst.com.my/news/nation/2021/05/686980/bookings-astrazenecavaccine-start-tomorrow.

42. Birruntha S. Khairy: No serious side effects from AstraZeneca vaccine so far. 2021 [Accessed 2021 May 21]; Available from: https://themalaysianreserve.com/2021/05/18/khairy-no-serious-sideeffects-from-astrazeneca-vaccine-so-far/.

43. Registration for second round of AstraZeneca opt-ins starts at noon Sunday (May 23). 2021 [Accessed 2021 May 21]; Available from: https://www.thestar.com.my/news/nation/2021/05/21/registration-forsecond-round-of-astrazeneca-opt-ins-starts-at-noon-saturday-may-23.

44. Ritchie H O-OE, Beltekian D, Mathieu E, Hasell J, Macdonald B, Giattino C, Appel C, Rodés-Guirao L, Roser M. Coronavirus Pandemic (COVID-19). [Online Resource] 2020 [Accessed 2021 May 23]; Available from: https://ourworldindata.org/coronavirus.

45. Progress Statistics for The National COVID-19 Immunisation Programme. 2021 [Accessed 2021 May 21]; Available from: https://www.vaksincovid.gov.my/statistik/.

46. Chong YM, Sam I-C, Chong J, et al., SARS-CoV-2 lineage B. 6 was the major contributor to early pandemic transmission in Malaysia. PLoS Negl Trop Dis 2020; 14(11): e0008744.

47. Syahida Mat Yassim A, Fazli Farida Asras M, Mahfuz Gazali A, et al., COVID-19 Outbreak in Malaysia: Decoding D614G Mutation of SARS-CoV-2 Virus Isolated from an Asymptomatic Case in Pahang. Materials today. Proceedings 2021: 10.1016/j.matpr.2021.02.387. 
48. Emergence of new Covid-19 variants worrying, says Health DG. 2021 [Accessed 2021 May 21]; Available from: https://www.theedgemarkets.com/article/emergence-new-covid19-variantsworrying-says-health-dg.

49. Abu-Raddad LJ, Chemaitelly H, and Butt AA, Effectiveness of the BNT162b2 Covid-19 Vaccine against the B. 1.1. 7 and B. 1.351 Variants. N Engl J Med 2021.

50. Madhi SA, Baillie V, Cutland CL, et al., Efficacy of the ChAdOx1 nCoV-19 Covid-19 vaccine against the B. 1.351 variant. N Engl J Med 2021.

51. Two COVID-19 shots effective against B16172 variant from India: English health body. 2021 [Accessed 2021 May 23]; Available from: https://www.channelnewsasia.com/news/world/two-covid19-shots-effective-against-india-variant-14867452.

Author(s) shall retain the copyright of their work and grant the Journal/Publisher right for the first publication with the work simultaneously licensed under:

Creative Commons Attribution-NonCommercial 4.0 International (CC BY-NC 4.0). This license allows for the copying, distribution and transmission of the work, provided the correct attribution of the original creator is stated. Adaptation and remixing are also permitted. 